\title{
Mesosphere summer echoes observed with the SuperDARN Hokkaido HF radar at Rikubetsu, Japan $\left(43.5^{\circ} \mathrm{N}\right)$
}

\author{
Tadahiko Ogawa ${ }^{1}$, Nozomu Nishitani ${ }^{2}$, Seiji Kawamura ${ }^{1}$, and Yasuhiro Murayama ${ }^{1}$ \\ ${ }^{1}$ National Institute of Information and Communications Technology, Tokyo 184-8795, Japan \\ ${ }^{2}$ Solar-Terrestrial Environment Laboratory, Nagoya University, Nagoya 464-8601, Japan
}

(Received May 2, 2013; Revised June 24, 2013; Accepted July 24, 2013; Online published December 6, 2013)

\begin{abstract}
Using the SuperDARN Hokkaido HF radar located at Rikubetsu in Hokkaido, Japan $\left(43.5^{\circ} \mathrm{N}\right)$, we present first oblique-incidence observations of midlatitude mesosphere summer echoes (MSE) at the HF band (HF-MSE). Three HF-MSE events in June 2009 are case-studied. Analyses of HF-MSE data together with VHF and MF radar data obtained at Wakkanai, $260 \mathrm{~km}$ northwest of Rikubetsu, indicate the following: (1) in two events HFMSE were accompanied by MSE at VHF (VHF-MSE), and in one event only HF-MSE were observed. (2) In accordance with southward neutral winds observed with the MF radar, HF-MSE exhibited high Doppler velocities with a maximum of about $60 \mathrm{~m} / \mathrm{s}$ toward the south, and also HF-MSE regions moved southward with time, suggesting that irregularities and/or cold ice particles responsible for the radar wave scattering might be advected southward from higher latitudes.
\end{abstract}

Key words: Mesosphere summer echoes, midlatitude mesosphere, VHF radar, HF radar, MF radar.

\section{Introduction}

Strong radar echoes, called polar mesosphere summer echoes (PMSE), from the cold summer mesopause region at high latitudes have been observed mainly with VHF radars (hereafter called VHF-PMSE) (e.g., Rapp and Lübken, 2004 and references therein; Bremer et al., 2006; Morris et al., 2009). It is believed that mesospheric neutral air turbulence and heavy charged ice aerosol particles are important for the creation of PMSE (Rapp and Lübken, 2004). VHF radar echoes similar to VHF-PMSE have been observed at higher midlatitudes in Germany (e.g., Reid et al., 1989; Latteck et al., 1999), the UK (Thomas et al., 1992), and Japan (Ogawa et al., 2011): these echoes, called mesosphere summer echoes (MSE), appear mainly at the 80-90 $\mathrm{km}$ altitudes. Though compared with VHF-PMSE, MSE at VHF (hereafter called VHF-MSE) exhibit rather rare occurrence and weak echo intensity, and appear only during the daytime, VHF-MSE are believed to be also related to the cold mesopause temperature (e.g., Gerding et al., 2007).

VHF radars used for PMSE and MSE observations are usually equipped with vertical and narrow beams, and have an altitude resolution of less than $1 \mathrm{~km}$. Vertical-incidence HF radars have also been used for PMSE detection (e.g., Ramos et al., 2009 and references therein). Ogawa et al. (2002, 2003) showed that PMSE are also detectable with an oblique-incidence Super Dual Auroral Radar Network (SuperDARN) HF radar (Greenwald et al., 1995; Chisham et al., 2007). This paper presents first MSE observations using a midlatitude SuperDARN radar located at Riku-

Copyright (C) The Society of Geomagnetism and Earth, Planetary and Space Sciences (SGEPSS); The Seismological Society of Japan; The Volcanological Society of Japan; The Geodetic Society of Japan; The Japanese Society for Planetary Sciences; TERRAPUB.

doi:10.5047/eps.2013.07.009 betsu in Hokkaido, Japan (e.g., Nishitani and Ogawa, 2005) to demonstrate the capability of midlatitude SuperDARN radars for MSE study. This HF radar provides horizontal two-dimensional distribution of MSE regions. However, it has a wide beam width in the vertical plane and a coarse range resolution, making it difficult to know exact echo altitudes. To overcome this problem, we use vertical-incidence VHF and MF radars located at Wakkanai in Hokkaido. MSE events observed with both radars in 2000 and 2009 have been reported by Ogawa et al. (2011). By using data from three radars, this paper discusses some new features of midlatitude MSE at HF (HF-MSE).

\section{Instrumentation}

Figure 1 shows a field of view (FOV) of the HF radar at Rikubetsu $\left(43.5^{\circ} \mathrm{N}, 143.6^{\circ} \mathrm{E}\right)$. The FOV is covered with 16 narrow beams (beam numbers $0,1,2, \ldots, 15$ ) over an azimuth sector of $52^{\circ}$. In this paper, two frequencies of about 11 and $9 \mathrm{MHz}$ are used. The antenna beam at $11 \mathrm{MHz}(9$ $\mathrm{MHz})$ has a horizontal width of about $5^{\circ}\left(6^{\circ}\right)$ and a maximum sensitivity at an elevation angle of about $30^{\circ}\left(33^{\circ}\right)$ with a half power width of about $30^{\circ}$. In the observations, the beam was sequentially scanned from beam 15 to beam 0 with a scan repeat time of $60 \mathrm{~s}$. The range resolution at 11 $\mathrm{MHz}(9 \mathrm{MHz})$ was $45 \mathrm{~km}(15 \mathrm{~km})$, and the first range gate at $11 \mathrm{MHz}(9 \mathrm{MHz})$ was set to $270 \mathrm{~km}(195 \mathrm{~km})$.

The VHF and MF radars are located at Wakkanai $\left(45.4^{\circ} \mathrm{N}, 141.8^{\circ} \mathrm{E}\right)$, about $260 \mathrm{~km}$ northwest of Rikubetsu (Fig. 1): see Ogawa et al. (2011) for the main technical parameters of both radars. In brief, the 46.5-MHz VHF radar with a peak power of $80 \mathrm{~kW}$ is equipped with 144 threeelement Yagis for transmission and reception, and has a beam width of $6^{\circ}$ in the vertical. The altitude and time resolutions are $600 \mathrm{~m}$ and $3 \mathrm{~min}$, respectively. The collo- 


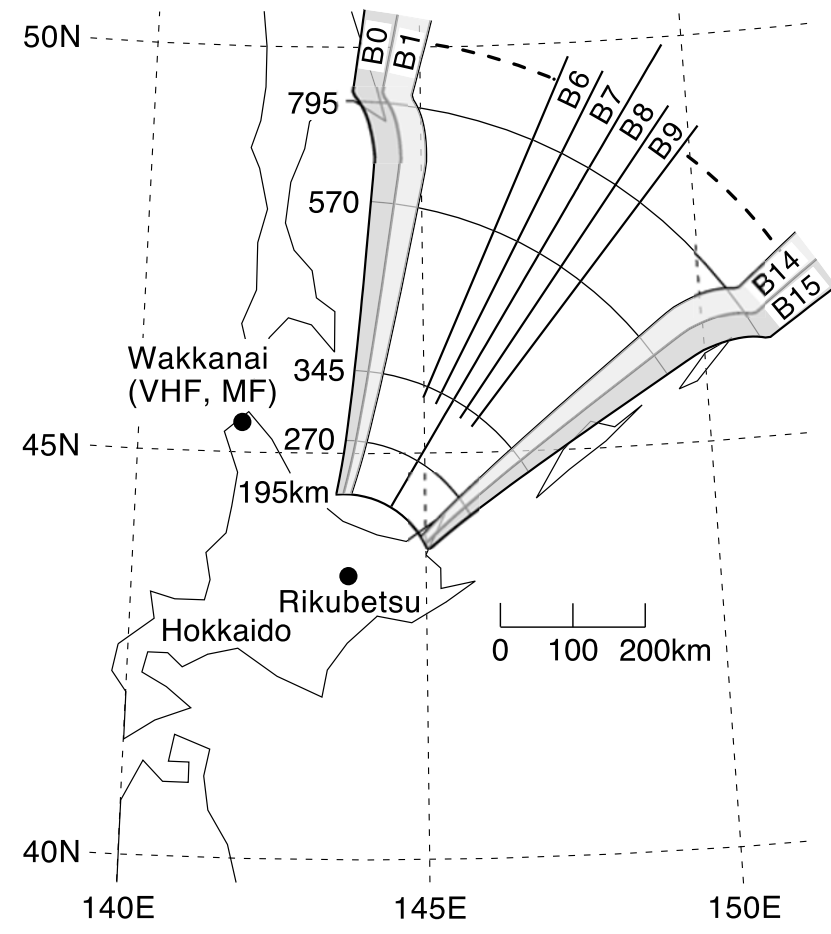

Fig. 1. FOV of the SuperDARN Hokkaido HF radar at Rikubetsu. Ground ranges from the radar site are indicated by solid curves. VHF and MF radars are located at Wakkanai, $260 \mathrm{~km}$ northwest of Rikubetsu.

cated $1.96-\mathrm{MHz}$ MF radar with a peak power of $50 \mathrm{~kW}$ is equipped with four crossed-dipole antennas for transmission and reception, and has a beam width of about $40^{\circ}$ in the vertical, and altitude and time resolutions of $2 \mathrm{~km}$ and 6 min, respectively. Horizontal winds are derived by using the conventional full correlation analysis method. Both radars detect echoes from a common volume over Wakkanai.

\section{Observations}

In this paper we examine three HF-MSE events in June 2009. At first, Fig. 2(a) shows range-time-intensity (RTI) plots of the HF radar echoes observed on beams 0-5 during 0700-0900 JST (JST $=\mathrm{UT}+9 \mathrm{~h}$ ) on 30 June 2009. The echoes with echo power higher than $20 \mathrm{~dB}$ are plotted in the figure to highlight MSE. The radar frequency and range resolution are $11.1 \mathrm{MHz}$ and $45 \mathrm{~km}$, respectively. Strong echoes with power exceeding $38 \mathrm{~dB}$ appear in the localized regions on some beams at around 0715-0735, 0745-0815 and 0825-0835 JST. The range-time-velocity (RTV) plots of the Doppler velocities are displayed in Fig. 2(b): note that plus (minus) sign means motion toward (away from) the radar site. As can be observed, the strong echoes have high positive velocities with a maximum of $60 \mathrm{~m} / \mathrm{s}$, indicating a southward (equatorward) motion of the echo targets. It is known that midlatitude VHF-MSE appear when neutral winds around echo altitudes have southward component (e.g., Gerding et al., 2007; Ogawa et al., 2011, and Figs. 3(a) and 3(c)), in line with the positive Doppler velocities observed with our oblique-incidence HF radar. We believe that the organized and localized echoes having strong echo powers (Fig. 2(a)) and high positive velocities (Fig. 2(b)) (and with narrow spectral widths less than 10 $\mathrm{m} / \mathrm{s}$; not shown) are a signature of HF-MSE. Note that HFand VHF-MSE appear only during the daytime in summer.

Most of the weak echoes $(\leq 38 \mathrm{~dB})$ with low velocities, say between -32 and $+32 \mathrm{~m} / \mathrm{s}$, (and with narrow spectral widths mostly less than $10 \mathrm{~m} / \mathrm{s}$; not shown) are randomly distributed in space and time. Surely, these are not coherent echoes returned from ionospheric field-aligned irregularities (FAIs), but echoes from meteors and due to scattering from the sea surface via $E$ or $F$ layer reflection: such echoes appear more or less on all the radar beams in Fig. 2 (also in Figs. 3 and 4). The sea surface scatter echoes are very popular ones at all seasons for the Hokkaido HF radar whose FOV is located over the Sea of Okhotsk (see Fig. 1) (e.g., Ogawa et al., 2012). Meanwhile, a routine ionosonde providing ionogram every $15 \mathrm{~min}$ is located at Sarobetsu, about $23 \mathrm{~km}$ south of the VHF and MF radar site. This ionosonde observed sporadic- $E\left(E_{\mathrm{s}}\right)$ layers with $f_{\mathrm{o}} E_{\mathrm{s}}$ between 6 and $12 \mathrm{MHz}$ during the HF-MSE event in Figs. 2(a) and (b), but no signatures of coherent echoes due to $E_{\mathrm{s}}$-FAIs are recognized in these figures.

Figure 2(c) shows two-dimensional Doppler velocity maps at 0718 and 0802 JST. In the 0718 JST map, the high velocity region was localized at ground ranges of 495-675 $\mathrm{km}$ on beams $0-4$. This high velocity region moved southward with time, as can be observed in Figs. 2(a) and 2(b), and at $0802 \mathrm{JST}$ it was located mainly at ranges of 315-540 $\mathrm{km}$ on beams $0-7$. After 0802 JST this high velocity region continued to move southward.

It is difficult to know exact echo altitudes from the current $\mathrm{HF}$ radar observations because the radar has the broad beam width $\left(\sim 30^{\circ}\right)$ in the vertical plane and the coarse range resolution $(45 \mathrm{~km})$. Here, we consult with VHF and MF radar data obtained at Wakkanai (Ogawa et al., 2011). Figure 3(a) displays altitude-time plot of the signal-to-noise ratios (SNR) observed with the VHF radar on the same day. After the short-lived, weak echoes at the $86-87 \mathrm{~km}$ altitudes at around $0820 \mathrm{JST}$, there appears a long-lasting ( $\sim 4$ hours) echo layer with a thickness of less than $3 \mathrm{~km}$. The layer altitudes are modulated due to short-period atmospheric gravity waves (AGW) with a period of about one hour, and descend gradually with time at about $0.3 \mathrm{~m} / \mathrm{s}$ due to tides (Ogawa et al., 2011). The RTV plot on the HF radar beam 1 is shown in Fig. 3(b), where the strong HF echoes with high positive velocities exist only at 0745-0820 JST before the VHF-MSE appearance at around 0820 JST. Note that the HF echo region at ranges of $300-450 \mathrm{~km}$ at around $0800 \mathrm{JST}$ is located at about $150-250 \mathrm{~km}$ east-northeast of Wakkanai (see Fig. 2(c)). The horizontal wind vectors, averaged over $18 \mathrm{~min}$, observed with the MF radar are plotted in Fig. 3(c) where the VHF-MSE areas in Fig. 3(a) are marked by rectangles. When VHF-MSE appear at altitudes of $84-89 \mathrm{~km}$ at around $0820 \mathrm{JST}$ and after $1000 \mathrm{JST}$, the winds at the same altitudes have southward (equatorward) component with a maximum of about $50 \mathrm{~m} / \mathrm{s}$ except for the period of 1000-1100 JST. Nearly simultaneous occurrence of VHF-MSE at the $86-87 \mathrm{~km}$ altitudes and HF-MSE during 0745-0820 JST suggest that the HF-MSE altitudes are also $86-87 \mathrm{~km}$ or $84-89 \mathrm{~km}$ where the winds advecting echo targets are southward to cause the positive Doppler velocities of HF-MSE. 
(a) Echo Power ( $\geq 20 \mathrm{~dB})$

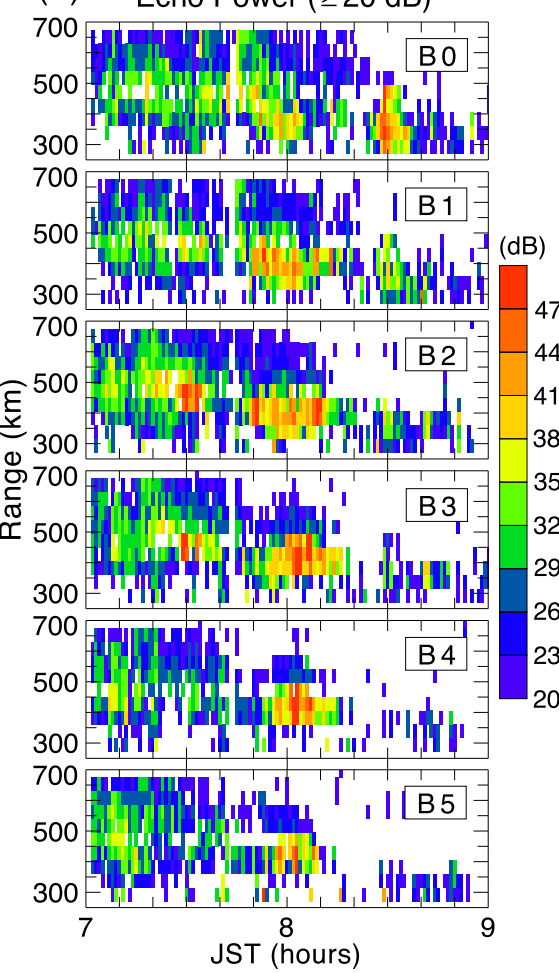

(b) Doppler Velocity ( $\mathrm{P} \geq 20 \mathrm{~dB})$

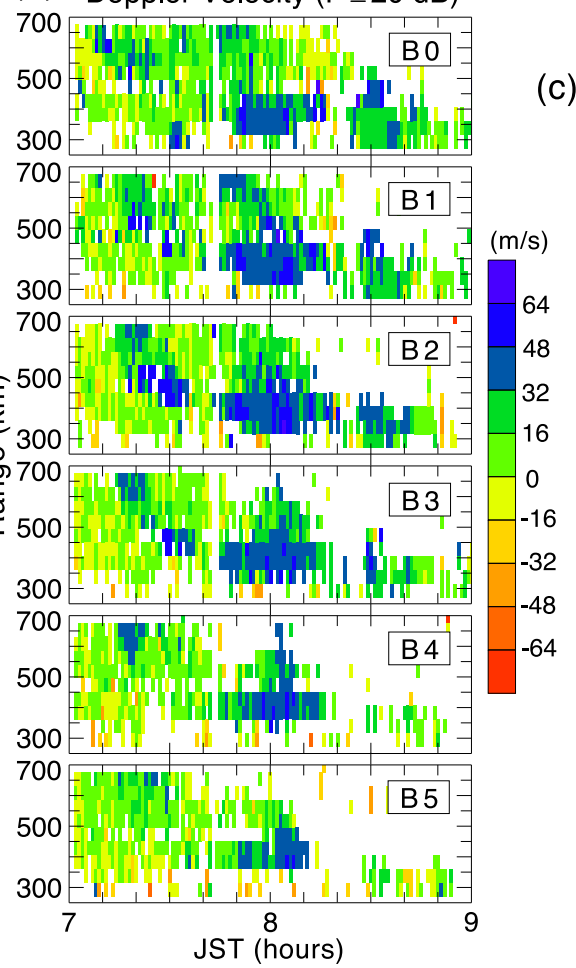

HF Radar 30 June 2009 11. $1 \mathrm{MHz}$

(c) Doppler Velocity $(\mathrm{P} \geq 20 \mathrm{~dB})$
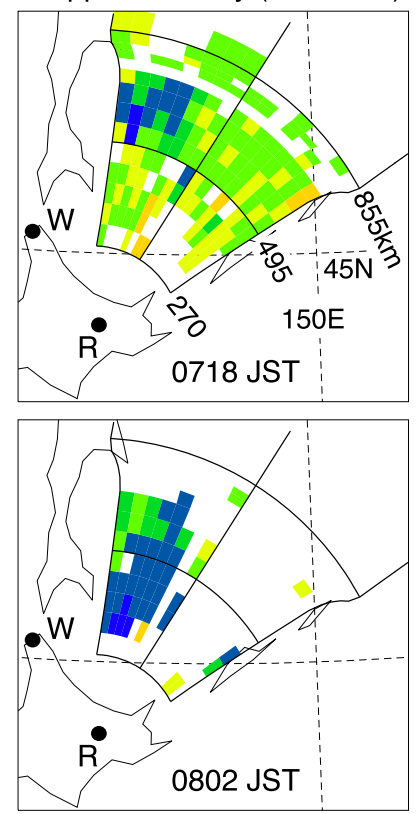

Fig. 2. (a) RTI and (b) RTV plots on HF radar beams 0-5, and (c) Doppler velocity maps at 0718 and 0802 JST on 30 June 2009.

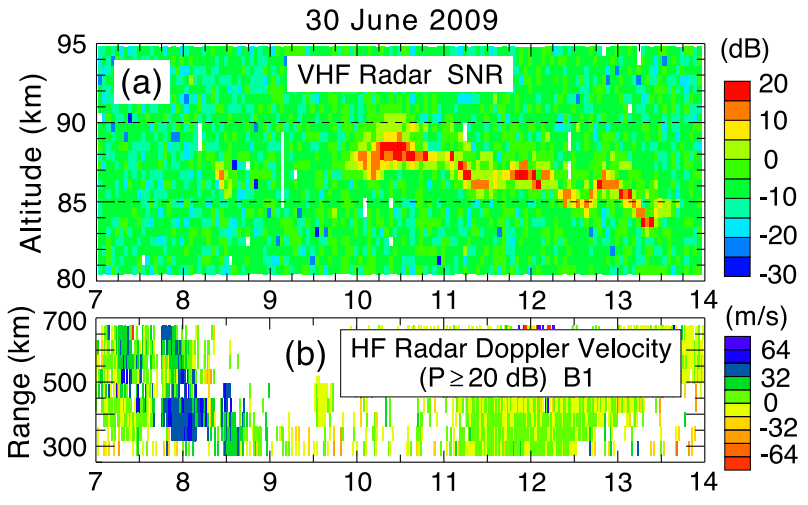

(c) Horizontal Wind (18-min Average)

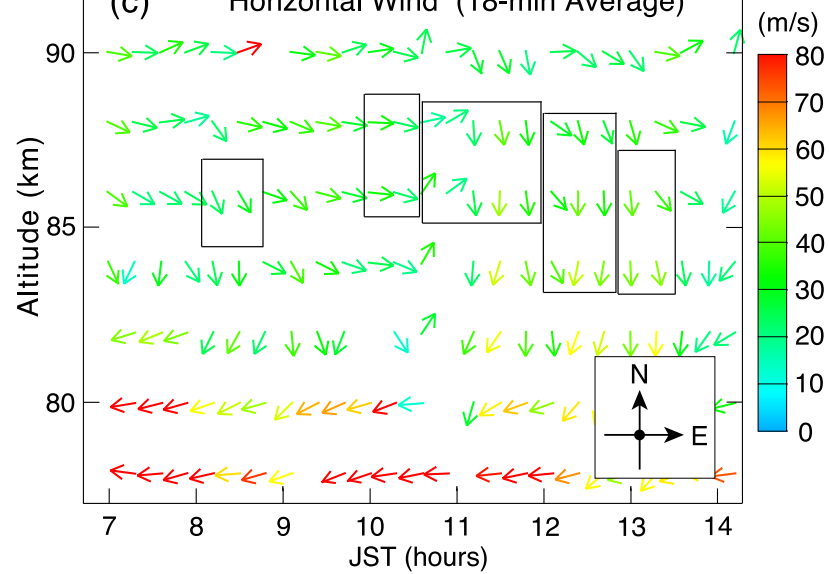

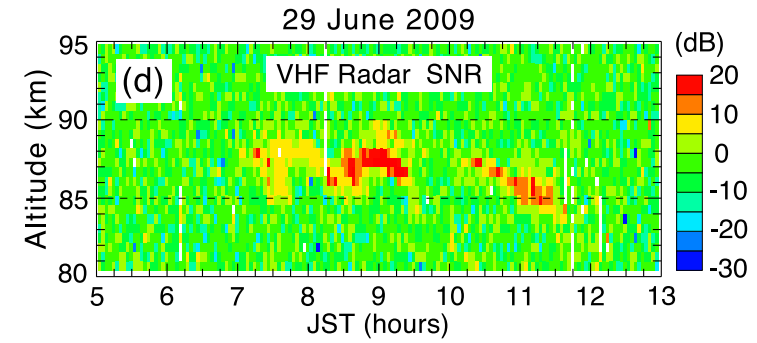

(e) HF Radar Doppler Velocity $(\mathrm{P} \geq 10 \mathrm{~dB}) 11.1 \mathrm{MHz}$
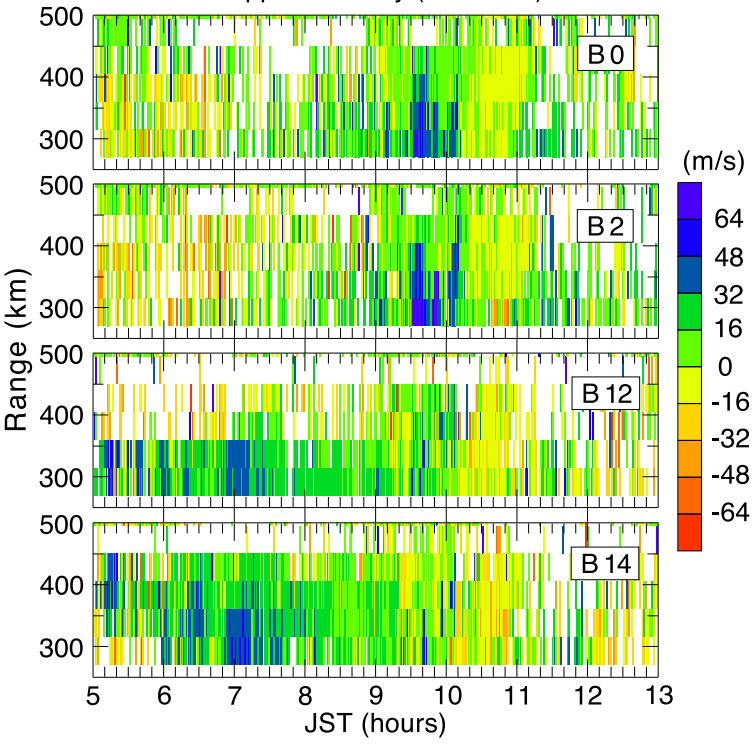

Fig. 3. (a) Altitude-time plot of VHF radar SNR, (b) RTV plot on HF radar beam 1, and (c) horizontal wind vectors (averaged over 18 min) as a function of altitude and time on 30 June 2009. The VHF-MSE areas in (a) are marked by rectangles in (c). (d) Altitude-time plot of VHF radar SNR and (e) RTV plots on HF radar beams 0, 2, 12 and 14 on 29 June 2009. 

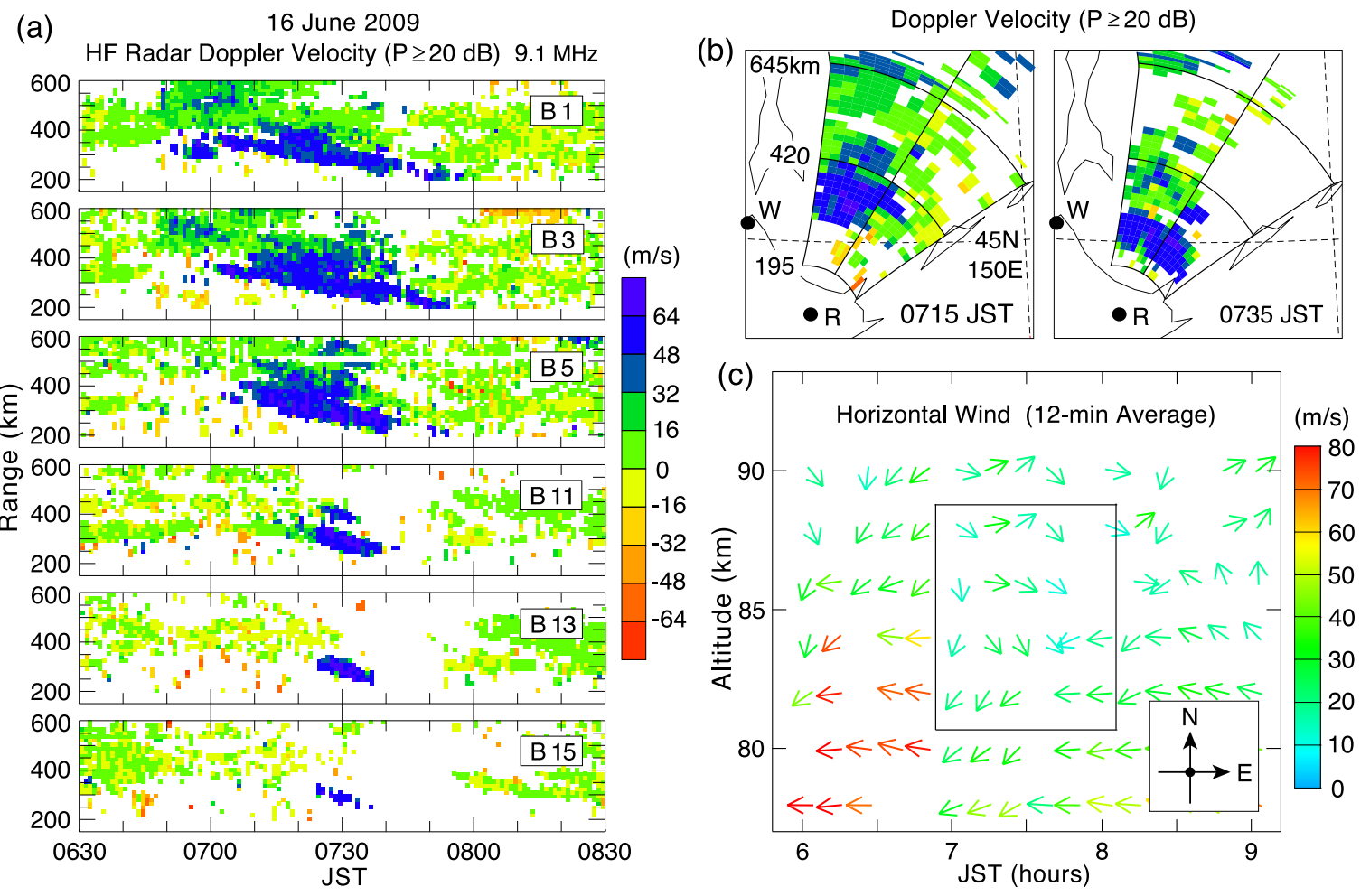

Fig. 4. (a) RTV plots on HF radar beams 1, 3, 5, 11, 13 and 15, (b) Doppler velocity maps at 0715 and 0735 JST, and (c) horizontal wind vectors (averaged over $12 \mathrm{~min}$ ) on 16 June 2009.

The second simultaneous VHF- and HF-MSE event on 29 June 2009 is shown in Figs. 3(d) and 3(e). In Fig. 3(d) VHF-MSE also modulated with short-period AGW appear at 83-90 km altitudes. Figure 3(e) displays RTV plots of the HF radar echoes (with echo power higher than 10 $\mathrm{dB})$ observed on beams $0,2,12$ and 14 . There appear high positive velocities with a maximum of about $50 \mathrm{~m} / \mathrm{s}$ at ranges of $270-400 \mathrm{~km}$ during $0600-0730 \mathrm{JST}$ on beams 12 and 14 (also on beams 10, 11, 13 and 15; not shown), and during 0930-1010 JST on beams 0 and 2 (also on beams 1 and 3-6; not shown). HF-MSE on beams 10-15 appear around the start of VHF-MSE, and those on beams 0-6 do during 0930-1010 JST when VHF-MSE subside for a while. The HF-MSE region on beams $10-15$ is located at about $200-300 \mathrm{~km}$ east of Wakkanai and that on beams 0-6 at about $150-250 \mathrm{~km}$ east-northeast of it. It is noted that $f_{\mathrm{o}} E_{\mathrm{s}}$ over Sarobetsu was less than $6 \mathrm{MHz}$ during the HFMSE event in Fig. 3(e), and that there appear no signatures of coherent echoes due to $E_{\mathrm{s}}$-FAIs in this figure. The meridional winds at $84-88 \mathrm{~km}$ altitudes during $0900-1200$ JST are southward with a maximum of about $40 \mathrm{~m} / \mathrm{s}$ (not shown), in line with the positive Doppler velocities of HFMSE. Unfortunately, the wind data before 0900 JST are not available.

In the above-mentioned two events, the HF-MSE occurrences are clearly related to VHF-MSE ones. In some cases, HF-MSE (VHF-MSE) were observed without any signatures of VHF-MSE (HF-MSE). As an example, Figs. 4(a) and 4(b) display an HF-MSE event, not accompanied by VHF-MSE, on 16 June 2009. Figure 4(a) shows RTV plot (with echo power higher than $20 \mathrm{~dB}$ ) observed on the HF radar beams $1,3,5,11,13$ nd 15 . The radar frequency and range resolution are $9.1 \mathrm{MHz}$ and $15 \mathrm{~km}$, respectively. Clearly, the echo regions with high positive Doppler velocities with a maximum of about $60 \mathrm{~m} / \mathrm{s}$ move southward with time and away from the radar FOV after $0800 \mathrm{JST}$. It is discernible from Fig. 4(b) that the main echo region exists at ranges of $285-480 \mathrm{~km}$ on beams $0-9$ at 0715 JST and at ranges of $225-300 \mathrm{~km}$ on beams $0-14$ at $0735 \mathrm{JST}$. Noteworthy is that $f_{\mathrm{o}} E_{\mathrm{s}}$ over Sarobetsu was less than $7 \mathrm{MHz}$ during 0630-0800 JST, and that no signatures of coherent echoes due to $E_{\mathrm{s}}$-FAIs are discernible in Figs. 4(a) and 4(b). In Fig. 4(c) the meridional winds (averaged over $12 \mathrm{~min}$ ) at 82-88 km during 0700-0800 JST are mostly southward.

It is noted that the high Doppler velocities appearing in Figs. 4(a) and 4(b) have strong echo powers, as demonstrated in Fig. 2, and narrow spectral widths of less than $10 \mathrm{~m} / \mathrm{s}$ (not shown): HF-MSE in Figs. 2 and 3(e) also have such narrow spectral widths.

\section{Discussion and Summary}

We have presented three examples of HF-MSE observations in June 2009 with the SuperDARN Hokkaido radar. HF-MSE on 30 June (Fig. 2) and 29 June (Fig 3(e)) are related to VHF-MSE over Wakkanai, $260 \mathrm{~km}$ northwest of Rikubetsu. Ogawa et al. (2011) have reported that VHFMSE on 30 June are accompanied by simultaneous MSE over Wakkanai at the MF band (MF-MSE). For the 29 June event, no echo power data from the MF radar are available, and therefore we do no know whether MF-MSE existed or not. HF-MSE on 16 June (Figs. 4(a) and 4(b)) are not accompanied by VHF-MSE, but by simultaneous MF-MSE at 84-90 km altitudes (not shown), indicating that HF-MSE are located somewhere at these altitudes. It is noted that a 
SuperDARN radar in Finland and a VHF radar in Sweden, being separated by $650 \mathrm{~km}$ each other, simultaneously observed PMSE at 80-90 km altitudes (Ogawa et al., 2003).

Plasma turbulence and/or electron density structure appearing around the cold mesopause are responsible for the generation of echoes at the VHF (wavelength $\sim 6 \mathrm{~m}$ ), HF $(\sim 30 \mathrm{~m})$, and MF $(\sim 150 \mathrm{~m})$ bands (e.g., Rapp and Lübken, 2004). VHF-PMSE are due to backscatter from Bragg-scale electron density irregularities. Partial reflection or Fresnel reflection from sharp electron density gradients along radar beam is another candidate for the backscatter. Partial reflection seems to dominate at the HF and MF bands (e.g., Röttger, 1994). In our observations, MSE did not always appear simultaneously at the three frequency bands, the reasons of which may be as follows: (1) when the plasma turbulence and structure have spectral components of the order of the above-mentioned wavelengths, simultaneous MSE appear at the three bands, while for example, when no components of $6 \mathrm{~m}$ or less exist, VHF-MSE are not expected. Moreover, the turbulent spectrum and plasma structure may be variable in space and time mainly due to short-period AGW. (2) The VHF and MF radars observe a common volume over Wakkanai, while the HF radar FOV is located at least $150 \mathrm{~km}$ to the east of Wakkanai. If the MSE region in the horizontal plane is wide enough to cover both the VHF and HF FOVs, HF-MSE and VHF-MSE are expected to be observed simultaneously. (3) HF-MSE are observed with the oblique-incidence HF radar, suggesting that scatterers inducing the HF backscatter are rather isotropic (weakly aspect sensitive) (e.g., Ogawa et al., 2002, 2003). If the scatterers are highly anisotropic (highly aspect sensitive), MSE would be detected with the vertical-incidence VHF and MF radars, but not with the oblique-incidence HF radar. See a paper by Rapp and Lübken (2004) for discussion about aspect sensitivity (i.e., signal dependence on radar beam tilted from the vertical direction) of VHF-PMSE.

HF-MSE exhibit high Doppler velocities with a maximum of about $60 \mathrm{~m} / \mathrm{s}$ toward the south, and the HF-MSE region move southward with time, both being consistent with the background meridional winds observed with the MF radar (Figs. 3(c) and 4(c)). The southward winds are also responsible for the VHF-MSE occurrence over Wakkanai (Ogawa et al., 2011). These facts suggest that irregularities and/or cold ice particles may be advected southward from higher latitudes, as already pointed out (e.g., Gerding et al., 2007; Morris et al., 2009).

Finally, we detected for the first time MSE at the HF band using a midlatitude SuperDARN HF radar in combination with VHF and MF radars. Surely, in the future we need to observe a common volume with three radars to answer some questions raised in this paper. The existing and planned $\mathrm{Su}-$ perDARN radars at midlatitude can contribute to the better understanding of midlatitude MSE.
Acknowledgments. This work was supported by a Grant-in-Aid for Scientific Research of the Ministry of Education, Culture, Sports, Science and Technology (MEXT) of Japan (19340141), and also by Special Funds for Education and Research (Energy Transport Processes in Geospace) of MEXT.

\section{References}

Bremer, J., P. Hoffman, J. Höffner, R. Latteck, W. Singer, M. Zecha, and O. Zeller, Long-term changes of mesospheric summer echoes at polar and middle latitudes, J. Atmos. Sol.-Terr. Phys., 68, 1940-1951, 2006.

Chisham, G. et al., A decade of the Super Dual Auroral Radar Network (SuperDARN): scientific achievements, new techniques and future directions, Surv. Geophys., 28, 22-109, 2007.

Gerding, M., J. Höffner, M. Rauthe, W. Singer, M. Zecha, and F.-J. Lübken, Simultaneous observation of noctilucent clouds, mesospheric summer echoes, and temperature at a midlatitude station $\left(54^{\circ} \mathrm{N}\right), J$. Geophys. Res., 112, D12111, doi:10.1029/2006JD008135, 2007.

Greenwald, R. A. et al., DARN/SuperDARN: A global view of the dynamics of high-latitude convection, Space Sci. Rev., 71, 761-796, 1995.

Latteck, R., W. Singer, and J. Höffner, Mesosphere summer echoes as observed by VHF radar at Külungsborn $\left(54^{\circ} \mathrm{N}\right)$, Geophys. Res. Lett., 26, 1533-1536, 1999.

Morris, R. J., A. R. Klekociuk, R. Latteck, W. Singer, D. A. Holdsworth, and D. J. Murphy, Inter-hemispheric asymmetry in polar mesosphere summer echoes and temperature at $69^{\circ}$ latitude, J. Atmos. Sol.-Terr. Phys., 71, 454-469, 2009.

Nishitani, N. and T. Ogawa, Model calculations of possible ionospheric backscatter echo area for a mid-latitude HF radar, Adv. Polar Upper Atmos. Res., 19, 55-62, 2005.

Ogawa, T., N. Nishitani, N. Sato, H. Yamagishi, and A. S. Yukimatu, Upper mesosphere summer echoes detected with the Antarctic Syowa HF radar, Geophys. Res. Lett., 29(7), 1157, doi:10.1029/2001GL014094, 2002.

Ogawa, T., N. F. Arnold, S. Kirkwood, N. Nishitani, and M. Lester, Finland HF and Esrange MST radar observations of polar mesosphere summer echoes, Ann. Geophys., 21, 1047-1055, 2003.

Ogawa, T., S. Kawamura, and Y. Murayama, Mesosphere summer echoes observed with VHF and MF radars at Wakkanai, Japan $\left(45.4^{\circ} \mathrm{N}\right), J$. Atmos. Sol.-Terr. Phys., 73, 2132-2141, 2011.

Ogawa, T., N. Nishitani, T. Tsugawa, and K. Shiokawa, Giant ionospheric disturbances observed with the SuperDARN Hokkaido HF radar and GPS network after the 2011 Tohoku earthquake, Earth Planets Space, 64, 1295-1307, 2012.

Ramos, C., M. C. Kelley, F. T. Djuth, K. M. Groves, Y. Murayama, S. Kawamura, and D. Thorsen, Multifrequency observations of Polar Mesosphere Summer Echoes using Alaskan radar facilities: Comparisons and scattering calculations, Radio Sci., 44, RS0511, doi:10.1029/2008RS004102, 2009.

Rapp, M. and F.-J. Lübken, Polar mesosphere summer echoes (PMSE): review of observations and current understanding, Atmos. Chem. Phys., 4, 2601-2633, 2004.

Reid, I. M., P. Czechowsky, R. Rüster, and G. Schmidt, First VHF radar measurements of mesopause summer echoes at mid-latitudes, Geophys. Res. Lett., 16, 135-138, 1989.

Röttger, J., Polar mesosphere summer echoes: Dynamics and aeronomy of the mesosphere, Adv. Space Res., 14(9), 123-137, 1994.

Thomas, L., I. Astin, and I. T. Prichard, The characteristics of VHF echoes from the summer mesopause region at mid-latitudes, J. Atmos. Terr. Phys., 54, 969-977, 1992.

T. Ogawa (e-mail: taogawa@nict.go.jp), N. Nishitani, S. Kawamura, and Y. Murayama 